\section{Léon Rosenfeld}

LÉon Rosenfeld was born at Charleroi, Belgium, on August 14, 1904. He studied physics and mathematics at the Université de Liège where he obtained a D.Sc. in 1926. He was associated with L. de Broglie and P. Langevin in Paris (1926-27) with M. Born in Göttingen (1927-29) and with W. Pauli in Zurich (1929-30). During this period he also collaborated with Th. De Donder in Brussels. In 1930 Rosenfeld visited Copenhagen, where he began a collaboration with Niels Bohr which lasted until Bohr's death in 1962. Rosenfeld joined the Université de Liège in 1930. From 1940 to 1947 he was Professor at the University of Utrecht and from 1947 to 1958 at the University of Manchester. In 1958 Rosenfeld became a professor at NORDITA.

Léon Rosenfeld was a member of the Royal Danish Academy, the Académie Royale de Belgique, the Académie Internationale d'Histoire des Sciences and the Academie Internationale de Philosophie des Sciences. He received the Prix Francqui, a high Belgian distinction, in Brussels in 1949.

The scientific interests of Léon Rosenfeld were unusually wide. They included quantum electrodynamics, nuclear physics, statistical mechanics, epistemology and history of sciences. His monographs Nuclear Forces (1948) and Theory of Electrons (1959) had a wide circulation.

His best known contribution is probably his fundamental paper with Niels Bohr in 1933 on the measurability of electromagnetic quantities. In this paper Bohr and Rosenfeld showed that the only meaningful statements of quantum theory when applied to electrodynamics concern averages of field components over finite space time regions. In this way they proved the logical consistency of quantum electrodynamics.

Another series of well-known papers by Rosenfeld, mostly in collaboration with Humblet from Liège, concerns the theory of nuclear reactions (1962-65). These papers introduced a new and precise definition of resonant states.

All his life Rosenfeld was deeply interested in the foundations of physics. The 'Copenhagen' interpretation of quantum mechanics, still accepted by the majority of physicists, was developed by Bohr and Rosenfeld following the pioneering work of Heisenberg, Born and Bohr.

After Bohr's death Rosenfeld appeared as his natural spiritual heir. It would be a mistake, however, to consider Rosenfeld as simply the guardian of the Copenhagen orthodoxy. More than anyone else he knew that one of the main objects of theoretical physics is to define the precise domain of validity of concepts involved in the mathematical models of physical reality. $\mathrm{He}$ wrote, "No physical concept is sufficiently defined without the knowledge of its domain of validity". For this reason he devoted most of his efforts during the last years of his life to showing that the coherence of the rules of quantum mechanics can be tested explicitly through the study of the dynamics of large systems. For him the founda- tions of quantum mechanics had not to be looked for in some axiomatic formulation valid for small systems with a discrete spectrum energy but, on the contrary, in the study of the limiting procedures involved in going to large systems. Since his early work he emphasised that there should exist a new type of complementarity between the "irreversible character of the macroscopic behaviour of the large systems and the time reversal invariance of its dynamical description at the atomic level". The outcome of these considerations is a generalised transformation theory which he developed in close collaboration with Prigogine's group in Brussels and in Austin. This transformation theory makes it possible to go from the usual representation of dynamics in terms of the Liouville-von Neumann operator $L$ to a new representation in which the contributions responsible for irreversible processes are explicitly displayed.

His fatal illness brutally interrupted his contribution to the promising new development in theoretical physics.

For Rosenfeld science was a total engagement. Far from being a simple intellectual curiosity, Rosenfeld, like Bohr, "conceived science as a human endeavour to achieve harmony with nature, a common task to which it was the earnest duty of each individual scientist to contribute his share".

Rosenfeld will be remembered and missed by all his friends and scientific collaborators who had the privilege of knowing him and of appreciating his exceptional personal, moral and intellectual qualities.

\section{Announcements}

\section{Appointments}

M. A. Sleigh has been appointed to the chair of biology at the University of Southampton (corrected announcement).

K. C. Calman has been appointed the Cancer Research Campaign Professor of Oncology at the University of Glasgow.

\section{International meetings}

September 10-11, Energy Conservation Conference, Glasgow (National Engineering Laboratory, East Kilbride, Glasgow G75 0QU).
September 23-26, International Symposium on Contamination Control, London (The Sam Black Organisation Ltd, 4 Harmsworth Way, London N20 8JU).

September 24, Symposium on Human and Veterinary Trematode Infections, London (Dr A. B. Simmonds, Chelsea College, Manresa Road, London SW3).

October 1-3, 1st National Topical Meeting on Nuclear Process Heat Applications, New Mexico (Robert Y. Porton, Public Relations Office, Los Alamos Scientific Laboratory, PO Box 1663, Los Alamos, New Mexico 87544).
October 21, Chemical and Mechanical Energy-Utilisation in Agriculture (Assistant Secretary, Society of Chemical Industry, 14 Belgrave Square, London SW1X 8PS).

\section{Erratum}

In the article "Ionisation ledges in the equatorial ionosphere" by R. Raghavarao and M. R. Sivaraman (Nature, 249,331 ; 1974) the first sentence of the third paragraph should read, The cusps were observed on ISIS-2 ionograms from the dip latitude region $9^{\circ} \mathrm{N}$ to $7.5^{\circ} \mathrm{S}$ recorded at Ahmedabad on October 6, 1972.

The reference number for equation (1) should be 5 instead of 4 . 